\title{
Single Tree Vegetation Depth Estimation Tool for Satellite Services Link Design
}

\author{
Zeynep HASIRCI, I. Hakki CAVDAR, Mehmet OZTURK \\ Dept. of Electrical and Electronics Engineering, Karadeniz Technical University, 61080 Trabzon, Turkey \\ \{zhasirci, cavdar, mehmetozturk\}@ktu.edu.tr \\ Manuscript received September 4, 2015
}

\begin{abstract}
Attenuation caused by tree shadowing is an important factor for describing the propagation channel of satellite services. Thus, vegetation effects should be determined by experimental studies or empirical formulations. In this study, tree types in the Black Sea Region of Turkey are classified based on their geometrical shapes into four groups such as conic, ellipsoid, spherical and hemispherical. The variations of the vegetation depth according to different tree shapes are calculated with ray tracing method. It is shown that different geometrical shapes have different vegetation depths even if they have same foliage volume for different elevation angles. The proposed method is validated with the related literature in terms of average single tree attenuation. On the other hand, in order to decrease system requirements (speed, memory usage etc.) of ray tracing method, an artificial neural network is proposed as an alternative. A graphical user interface is created for the above processes in MATLAB environment named vegetation depth estimation tool (VdET).
\end{abstract}

\section{Keywords}

MATLAB $^{\text {TM }}$ estimation tool, ray tracing, satellite services, tree attenuation, tree shape, vegetation depth

\section{Introduction}

In the communication area, signal attenuation is a major problem and many researches have been aimed to model in different links such as land mobile satellite communications, terrestrial mobile communication (GSM, 3G, $4 \mathrm{G}$ etc.) and high altitude platforms (HAPs). Because vegetation is a reason of attenuation, influence of vegetation on different communication links has been studied as an important issue. The previous studies focused on attenuation due to trees for both satellite and terrestrial links and many experimental results were reported at different frequency bands, for different tree types, in different seasonal effects, etc. There are many experiments such as single tree measurements and attenuation measurements. Average attenuation of trees was measured for land mobile satellites at UHF and L band by Vogel and Goldhirsh [1]-[3], Butterworth [4], [5], Ulaby et al. [6], and Cavdar [7]. In [1] and [2], largest and average attenuations and attenuation coefficients for different tree types were measured at UHF band. The ITU-R [8] also described attenuation through vegetation. At L-band, Cavdar et al. [9] conducted measurement. In [3] and [10], static tree attenuation measurements were performed in Austin, Texas at L- and K-band. Moreover, fade statistics for shadowing from roadside trees were measured at UHF and L bands in 1985, 1986, and 1987 [11]. In [12], single tree attenuation was examined with the help of measurements at $1-4 \mathrm{GHz}$ frequency band for $45^{\circ}$ elevation angle. The frequency dependence of vegetation effects for satellite links was studied in [13] and some attenuation measurements were performed at L-, S- and C-bands taking into consideration elevation angles between $25^{\circ}$ and $90^{\circ}$ [14]. Tree shadowing effects on wideband channel at $3.1 \mathrm{GHz}$ and $5.8 \mathrm{GHz}$ were studied in [15]. Additionally, for different terrestrial scenarios and different frequency bands, ITU-R Recommendation [16] also includes vegetation attenuation models not valid for high elevation scenarios. In [17], models and measurements for land mobile satellite system were published.

The vegetation attenuations can be only determined by experimental studies as summarized in the previous paragraph. It can reach a judgment in bold outline about the signal attenuation of the trees. However, the experimental results obtained vary significantly according to seasonal effects, type and size of trees, geographical locations etc. Furthermore, the trees in different geographical locations can have different sizes even if they are the same species. Therefore, providing generalized results obtained from the measurements to link designer is not an appropriate approach instead using empirical formulations such as $L=A d^{B} f^{C}$ [18] where $d$ represents vegetation depth. Vegetation depth is defined as the length of signal path within the tree canopy. It is easily concluded that vegetation depth is a significant factor for calculating attenuation correctly. Different tree types have different shapes and the tree geometry is very important to calculate the vegetation depths for different elevation angles. In the previous studies, all tree types are considered to have the same geometry and calculations were made with respect to this 
acceptance without considering tree shape. In this regard, we focus on single tree vegetation depth based on four different tree types such as conic, ellipsoid, spherical and hemispherical. For these four different classifications, the tree species especially in the Black Sea Region of Turkey are used. Thus, firstly, trees are grouped in four different shapes and are modeled in MATLAB environment. Their average heights and foliage volume data are taken from [19] for full leaves situation. According to the elevation angles between $0^{\circ}$ and $90^{\circ}$, vegetation depths are calculated for each tree types via the models with ray tracing method. Due to the need of high system resources, especially for ray tracing process, it is not useful to implement a practical software. Thus, utilization of artificial neural network (ANN) is proposed to estimate the vegetation depths more efficiently. All the works mentioned above are wrapped in a Graphical User Interface (GUI) named VdET (vegetation depth estimation tool).

\section{Method of Tree Modeling and Vegetation Depth Calculation}

The Black Sea is a geographically rich region comprised of deep green forests and there are many different tree types. In this study, both common and endemic tree types are investigated and are classified according to their geometrical shape. In Fig. 1, Fig. 2, Fig. 3, Fig. 4; spherical, hemispherical, conic and ellipsoid shape tree types are shown, respectively.

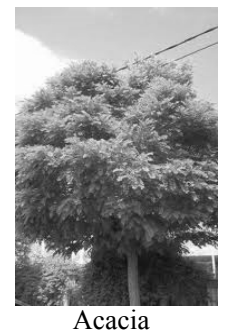

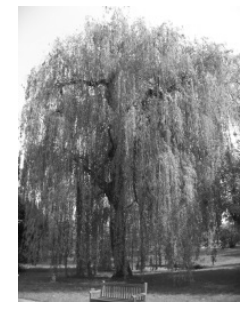

Salix Alba

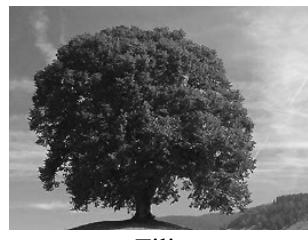

Tilia
Fig. 1. Investigated trees (spherical shape).

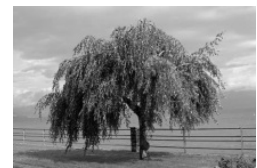

Betula Pendula

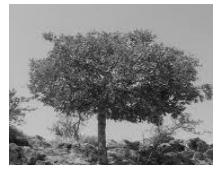

Celtis Caucasica

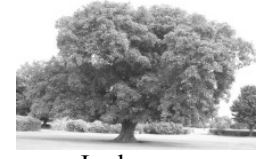

Juglans
Fig. 2. Investigated trees (hemispherical shape).

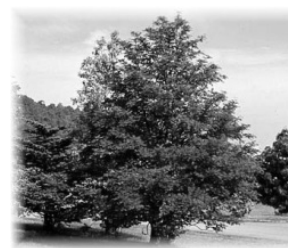

Fraxinus Excelsior

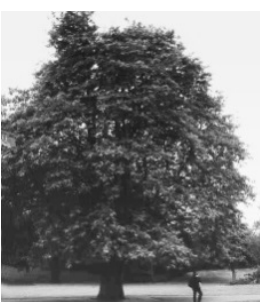

Platanus Orientalis

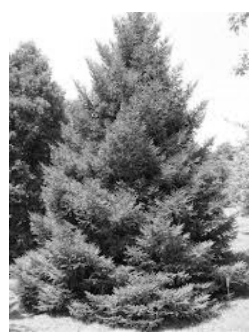

Picea Orientalis

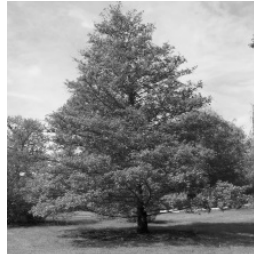

Alnus Glutinosa

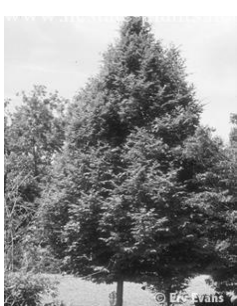

Carpinus Orientalis

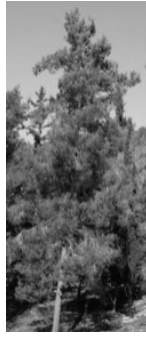

Pinus Brutia

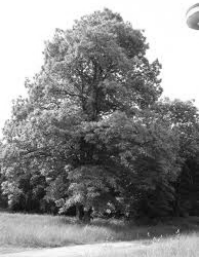

Castanea Sativa

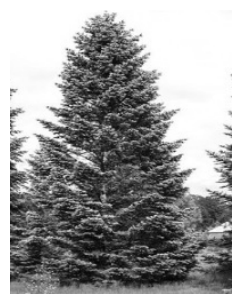

Abies Nordanniana

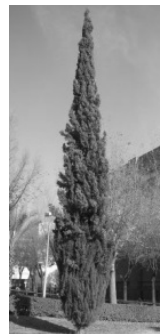

Cupressus Sepervirens
Fig. 3. Investigated trees (conic shape).

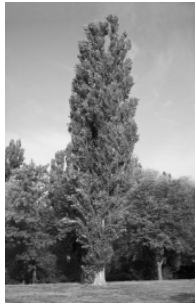

Populus Nigra

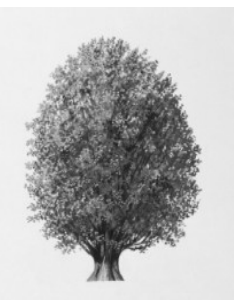

Zelkova Carpinifolia

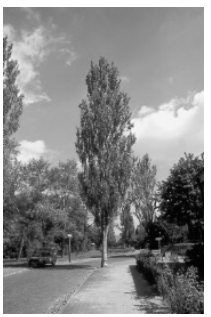

Populus Alba

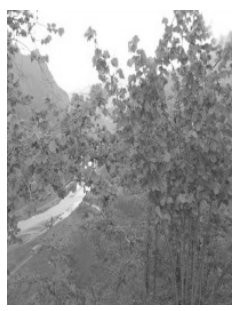

Corylus Colurna
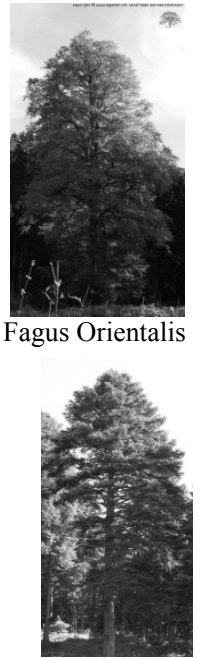

Pinus Nigra

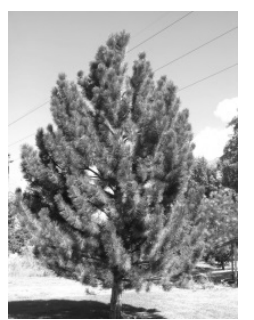

Pinus Sylvestris

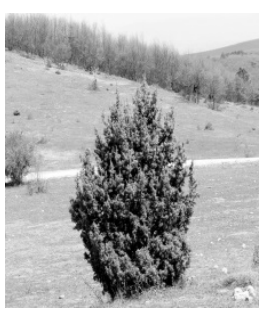

Juniperus Oxycedrus
Fig. 4. Investigated trees (ellipsoid shape). 


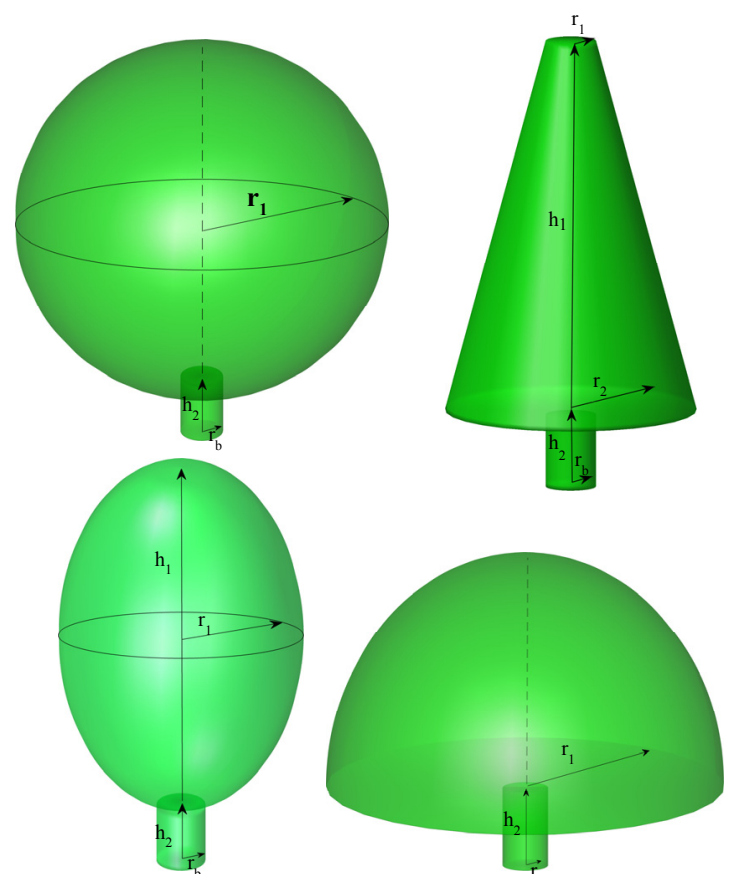

Fig. 5. Four different geometrical tree models with full leaves.

More information regarding signal derogation effects of trees at different frequencies and at different geographic locations is required for link design of satellite services (satellite and land mobile satellite communication, HAPs, etc.) It is important to search on new data belonging to different tree types for a proper system design and tree attenuation analysis. In this context, tree types in the Black Sea Region of Turkey are classified according to their geometrical shape due to different shapes engender different vegetation depths for the same elevation angles.

The two categories of trees are known as coniferous and deciduous and they have generally non-uniform and different shapes. However, if trees are supposed to have full leaves, they can be classified in four groups such as conic, ellipsoid, spherical and hemispherical as shown in Fig. 5.

A general geometric tree model has five parameters. These are $h_{1}, h_{2}, r_{1}, r_{2}, r_{\mathrm{b}}$. $h_{1}$ stands for height of foliage part, $h_{2}$ represents bole height of the tree, $r_{1}$ and $r_{2}$ are maximum and minimum radius of the foliage, respectively. $r_{\mathrm{b}}$ is radius of the bole. All these parameters are in meters. Tree classes and their parameters are listed in Tab. 1. In this study, main purpose is to estimate the vegetation depth of only foliage part. Thus, only $h_{1}, r_{1}$ and $r_{2}$ parameters which define foliage part are included in simulation (bold characters in Tab. 1).

\begin{tabular}{|c|c|}
\hline Tree Class & Parameters \\
\hline Conic & $\boldsymbol{h}_{\mathbf{1}}, h_{2}, \boldsymbol{r}_{\mathbf{1}}, \boldsymbol{r}_{\mathbf{2}}, r_{\mathrm{b}}$ \\
\hline Ellipsoid & $\boldsymbol{h}_{\mathbf{1}}, h_{2}, \boldsymbol{r}_{\mathbf{1}}, r_{\mathrm{b}}$ \\
\hline Spherical & $h_{2}, \boldsymbol{r}_{\mathbf{1}}, r_{\mathrm{b}}$ \\
\hline Hemispherical & $h_{2}, \boldsymbol{r}_{\mathbf{1}}, r_{\mathrm{b}}$ \\
\hline
\end{tabular}

Tab. 1. Tree classes and involved parameters.

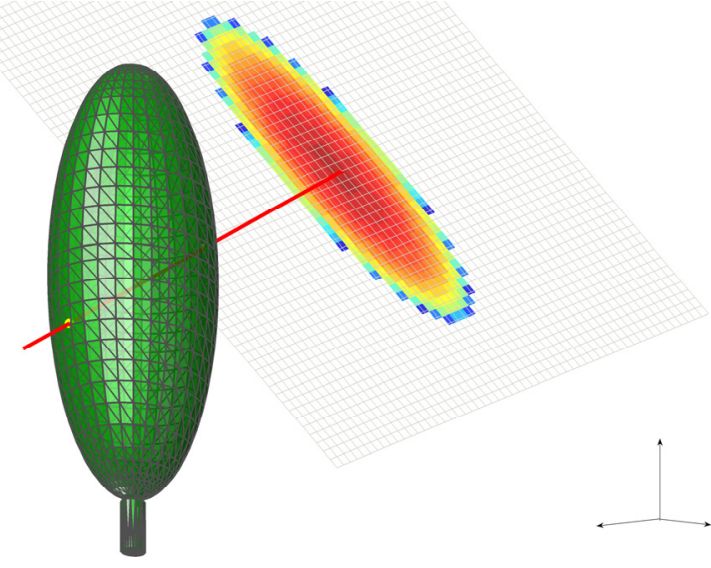

Fig. 6. An example from ray tracing process.

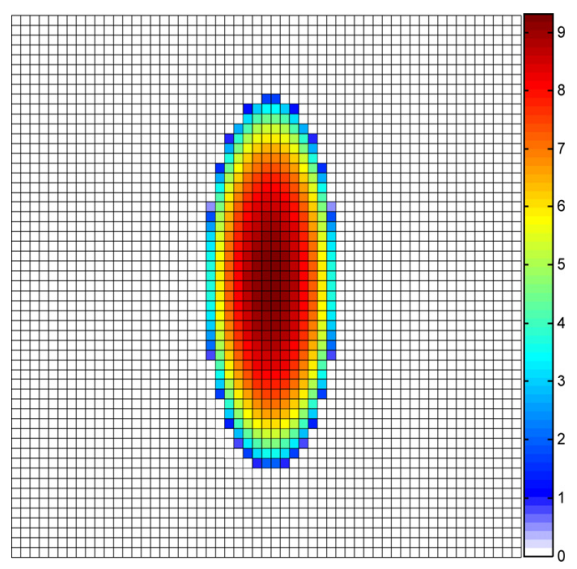

Fig. 7. A sample projection image of a grid for $45^{\circ}$.

The vegetation depths for each elevation angle are calculated with the help of ray tracing method over the geometrical tree models presented above. Ray tracing is a technique to simulate the effects of the ray's encounters with virtual objects like our tree models. In this case, the ray will intersect the tree models at exactly two points due to the fact that the models are finely closed surfaces. Vegetation depth is the distance between those two points. In Fig. 6, a single ray for a certain angle is shown.

Ray tracing process is realized over a rectangular grid as shown in Fig. 6. For this purpose, firstly a sphere is calculated such that the entire tree model is inscribed. Then, a cube is defined with the radius of the sphere to ensure the grid covers the entire tree model for every possible situation. Each point of this grid will be a starting point of a single ray. And also for each elevation angle, this grid is adjusted according to the ray direction. So, entire tree model is traced for all elevation angles $\left(0-90^{\circ}\right)$. In Fig. 7, a sample projection image of a grid for $45^{\circ}$ is shown. White colored grid represents no intersection regions while other colors mean there are different levels of intersection (vegetation depths).

To calculate the vegetation depths, tree classes and their involved parameters are needed. The parameters and categories of the conic, ellipsoid, spherical and hemispheri- 


\begin{tabular}{|c|c|c|c|c|c|c|c|}
\hline Tree Names & Height & Category & $\mathbf{h}_{\mathbf{1}}$ & $\mathbf{h}_{\mathbf{2}}$ & $\mathbf{r}_{\mathbf{1}}$ & $\mathbf{r}_{\mathbf{2}}$ & $\mathbf{r}_{\mathbf{b}}$ \\
\hline Fraxinus Excelsior & $30-40 \mathrm{~m}$ & Deciduous & 35 & 2 & 6 & 15 & 0.8 \\
\hline Alnus Glutinosa & $20-30 \mathrm{~m}$ & Deciduous & 28 & 2 & 1 & 14 & 0.8 \\
\hline Castanea Sativa & $20-25 \mathrm{~m}$ & Deciduous & 23 & 2 & 5 & 12 & 0.5 \\
\hline Platanus Orientalis & $20-30 \mathrm{~m}$ & Deciduous & 28 & 4 & 8 & 14 & 1.5 \\
\hline Carpinus Orientalis & $15-20 \mathrm{~m}$ & Deciduous & 15 & 5 & 1 & 6 & 0.2 \\
\hline Abies Nordanniana & $40-50 \mathrm{~m}$ & Coniferous & 45 & 1 & 2 & 10 & 0.5 \\
\hline Picea Orientalis & $40-60 \mathrm{~m}$ & Coniferous & 55 & 1 & 1 & 20 & 1.5 \\
\hline Pinus Brutia & $15-20 \mathrm{~m}$ & Coniferous & 15 & 3 & 1 & 3 & 0.3 \\
\hline Cupressus Sepervirens & $20-30 \mathrm{~m}$ & Coniferous & 29 & 1 & 0.3 & 2 & 0.5 \\
\hline
\end{tabular}

Tab. 2. Common conic tree types in the Black Sea Region.

\begin{tabular}{|c|c|c|c|c|c|c|}
\hline Tree Names & Height & Category & $\mathbf{h}_{\mathbf{1}}$ & $\mathbf{r}_{\mathbf{1}}$ & $\mathbf{h}_{\mathbf{2}}$ & $\mathbf{r}_{\mathbf{b}}$ \\
\hline Populus Nigra & $25-30 \mathrm{~m}$ & Deciduous & 28 & 4 & 1 & 1.5 \\
\hline Populus Alba & $20-30 \mathrm{~m}$ & Deciduous & 25 & 3.5 & 3 & 0.5 \\
\hline Fagus Orientalis & $30-40 \mathrm{~m}$ & Deciduous & 35 & 5 & 1 & 0.5 \\
\hline Zelkova Carpinifolia & $20-25 \mathrm{~m}$ & Deciduous & 20 & 8 & 2 & 2 \\
\hline Corylus Colurna & $2-4 \mathrm{~m}$ & Deciduous & 3 & 2.5 & 2 & 0.5 \\
\hline Pinus Nigra & $30-50 \mathrm{~m}$ & Coniferous & 40 & 7 & 7 & 1 \\
\hline Pinus Sylvestris & $20-40 \mathrm{~m}$ & Coniferous & 30 & 10 & 2 & 1 \\
\hline Juniperus Oxycedrus & $10-12 \mathrm{~m}$ & Coniferous & 10 & 4 & 0.5 & 0.1 \\
\hline
\end{tabular}

Tab. 3. Common ellipsoid tree types in the Black Sea Region.

\begin{tabular}{|c|c|c|c|c|c|}
\hline Tree Names & Height & Category & $\mathbf{r}_{\mathbf{1}}$ & $\mathbf{h}_{\mathbf{2}}$ & $\mathbf{r}_{\mathbf{b}}$ \\
\hline Acacia & $20-30 \mathrm{~m}$ & Deciduous & 10 & 5 & 0.5 \\
\hline Salix Alba & $25-30 \mathrm{~m}$ & Deciduous & 12 & 0.5 & 0.5 \\
\hline Juglans & $25-30 \mathrm{~m}$ & Deciduous & 12.5 & 1.5 & 2 \\
\hline Ulmus Glabra & $30-40 \mathrm{~m}$ & Deciduous & 17.5 & 5 & 1 \\
\hline Tilia & $30-40 \mathrm{~m}$ & Deciduous & 18 & 3 & 2 \\
\hline
\end{tabular}

Tab. 4. Common spherical tree types in the Black Sea Region.

\begin{tabular}{|c|c|c|c|c|c|}
\hline Tree Names & Height & Category & $\mathbf{r}_{\mathbf{1}}$ & $\mathbf{h}_{\mathbf{2}}$ & $\mathbf{r}_{\mathbf{b}}$ \\
\hline Betula Pendula & $20-25 \mathrm{~m}$ & Deciduous & 18 & 3 & 2 \\
\hline Celtis Caucasica & $5-6 \mathrm{~m}$ & Deciduous & 3 & 3 & 0.25 \\
\hline Quercus Cerris & $30-35 \mathrm{~m}$ & Deciduous & 35 & 3 & 1.2 \\
\hline
\end{tabular}

Tab. 5. Common hemispherical tree types in the Black Sea Region.

cal trees are given in Tab. 2, Tab. 3, Tab. 4, and Tab. 5, respectively.

To be able to show the effect of the tree shape on vegetation depths for different elevation angles, all trees are generated as they have the same volume of foliage. As shown in Fig. 8, vegetation depth corresponding to each elevation angle is different. Thus, all tree types should be handled separately to investigate the vegetation depth.

In ray tracing technique, for a single ray, each triangle of the tree model is tested for intersection. The total number of triangles depends on both the size of the tree and the

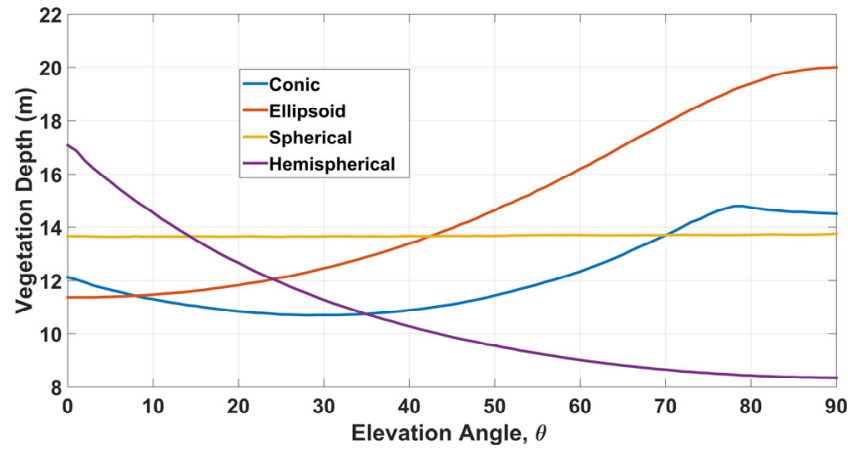

Fig. 8. Vegetation depth versus elevation angle for four different tree types with the same foliage volume $\left(4581.5 \mathrm{~m}^{3}\right)\left\{\left(h_{1}, r_{1}, r_{2}\right)_{\text {conic }}=(25,5,10),\left(h_{1}, r_{1}\right)_{\text {ellipsoid }}=\right.$ $\left.(30,8.54),\left(r_{1}\right)_{\text {spherical }}=(10.3),\left(r_{1}\right)_{\text {hemispherical }}=(12.98)\right\}$

desired spatial resolution. A smaller triangle means higher resolution. Graphical resolution should be kept as high as possible. It means that we need more number of triangles and more number of calculations. It is not practical. The criterion in determining the number of triangles is to obtain a visually satisfying graphic. In this study, the ratio of surface area to number of triangles is fixed to 0.5 which means a unit square area consists of two triangles. Proceeding from here, conducted experiments show that less than $0.2 \mathrm{~m}$ ray spacing does not improve spatial resolution except longer calculation time.

Ray tracing technique is ground truth for this simulation study, however, it requires high calculation capacity and system resources. Thus, this situation has made it necessary to search an alternative method. In this study, artificial neural network (ANN) is investigated for usability instead of ray tracing. The results of ANN are compared with ray tracing to reveal its effectiveness.

ANN is generally used with the situations where the input and output relation of a system is unknown or complex to model. ANN is influenced by biological neurons and their learning capability. It statistically learns the transfer function of the system by adjusting some number of coefficients. In this study, the training set consists of 25 trees in four different tree types. This different tree models have some parameters $\left(h_{1}, h_{2}, r_{1}, r_{2}, r_{\mathrm{b}}\right)$ defining their different shapes. To prepare training data, the range of each parameter should be defined. Thus, the variation range of tree model parameters is determined considering the parameters' minimum and maximum values. The ANN tries to minimize a cost function such that $[f(x)-y]^{2}$. In this function, $f$ represents the tree model while $x$ is input parameters $\left(h_{1}, h_{2}, r_{1}, r_{2}, r_{\mathrm{b}}\right)$ of that model. $y$ substitutes the vegetation depth obtained from ray tracing for input parameters of interest. The ANN training data for four different tree models are summarized below.

$$
\left\{\begin{array}{c}
{\left[f_{\text {conic }}\left(h_{1}^{i}, r_{1}^{i}, r_{2}^{i}\right)-y^{i}\right]^{2}, \quad i=1: 468} \\
h_{1} \in[15,20, \ldots, 55], \quad r_{1} \in[1,2, \ldots, 8], \quad r_{2} \in[2,4, \ldots, 20]
\end{array}\right\},
$$




$$
\begin{aligned}
& \left\{\begin{array}{c}
{\left[f_{\text {ellipsoid }}\left(h_{1}^{i}, r_{1}^{i}\right)-y^{i}\right]^{2}, i=1: 63} \\
h_{1} \in[10,15, \ldots, 40], \quad r_{1} \in[2,3, \ldots, 10]
\end{array}\right\}, \\
& \left\{\left[f_{\text {spherical }}\left(r_{1}^{i}\right)-y^{i}\right]^{2}, i=1: 11, \quad r_{1} \in[10,11, \ldots, 20]\right\}, \\
& \left\{\left[f_{\text {hemispherical }}\left(r_{1}^{i}\right)-y^{i}\right]^{2}, i=1: 16, \quad r_{1} \in[5,7, \ldots, 35]\right\} .
\end{aligned}
$$

Cross-validation method is utilized in training section to find optimal number of hidden layers. In this study, hidden layer numbers for conic, ellipsoid, spherical and hemispherical models are $14,12,1$ and 16, respectively.

\section{Vegetation Depth Estimation Tool (VdET)}

The Vegetation Depth Estimation Tool (VdET) is created in order to offer the users a practical simulation environment for performing vegetation depth calculation for different tree models. The GUI of our tool is shown in Fig. 9. The tool is programmed in MATLAB environment. However, for the sake of speed efficiency, some core functions such that ray-triangle intersection is coded in $\mathrm{C} / \mathrm{C}++$ language. The VdET is developed to handle different types of trees for simulation and testing with two methods; ray tracing and ANN. This GUI contains seven panels and a progress bar. The functionalities of each panel are stated below.

- Tree Type Selection Panel: This panel lets the user to select the type of tree (conic, ellipsoid, spherical, hemispherical) for simulation.

- Parameter Input Panel: After tree type selection, user enters related parameter values. Related parameters and their acceptable range are written according to the selected tree type and the program waits for an input value in defined range. These acceptable ranges are important especially for ANN results due to the training data are restricted as given in equations above.

- Calculation Method Panel: This panel contains three buttons. Ray Tracing and Artificial Neural Network buttons trigger the simulation. As the ray tracing method takes some time depending on the tree size (number of triangles), a progress bar helps the user to follow the percentage of process completed. Stop Execution button lets the user to terminate ray tracing anytime. Additionally, once the input parameters are given and a simulation is realized, these buttons will not trigger the same calculation again until there is a change in parameters.

- Ray Tracing Info Panel: This panel shows a 3D demonstration of ray tracing process. Users can observe not only the ray for a certain angle but also the rays for each elevation angles and intersection points.

- Simulation Result Graph Panel: In this panel, elevation angle vs. vegetation depth results of the two methods are shown in two graphics. While $x$-axis represents elevation angle (in degrees), y-axis shows vegetation depth values (in meters).

- Error Analysis Panel: If both ray tracing and ANN simulation results are obtained, error analyses are realized. The error is shown as a graph based on the difference of ray tracing from ANN. Additionally, root mean square error (RMSE), standard deviation (std) and maximum (max) of the error graph are listed.

- Simulation Result Export Panel: Numerical results shown in Simulation Result Graph Panel can be exported within this panel with three different file types *.mat, *.xlsx, *.txt. In this saved file, there are elevation angles, vegetation depths (from ray tracing and ANN separately) and error of ANN method.

In Fig. 10, all the simulation results are completed and graphed with the error statistics.

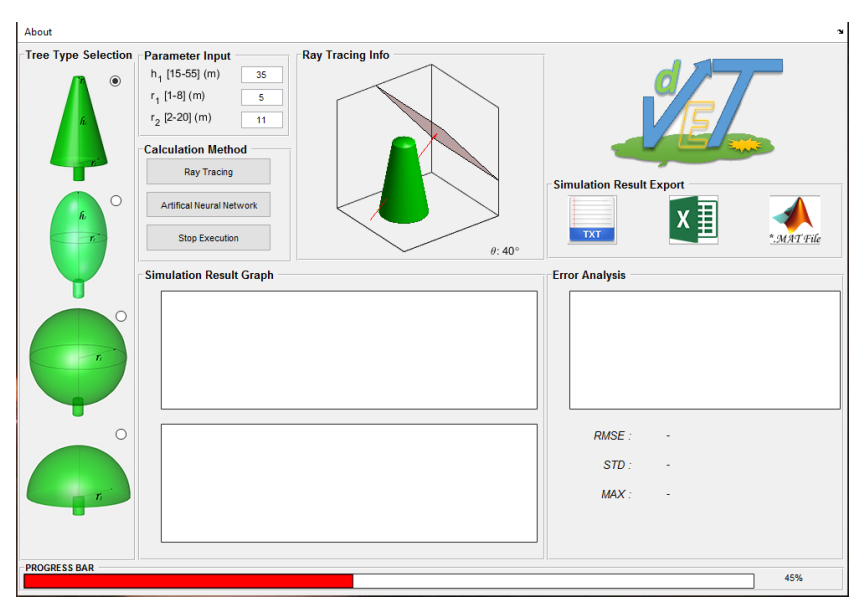

Fig. 9. An example image of the GUI at the process of raytracing for conic tree type.

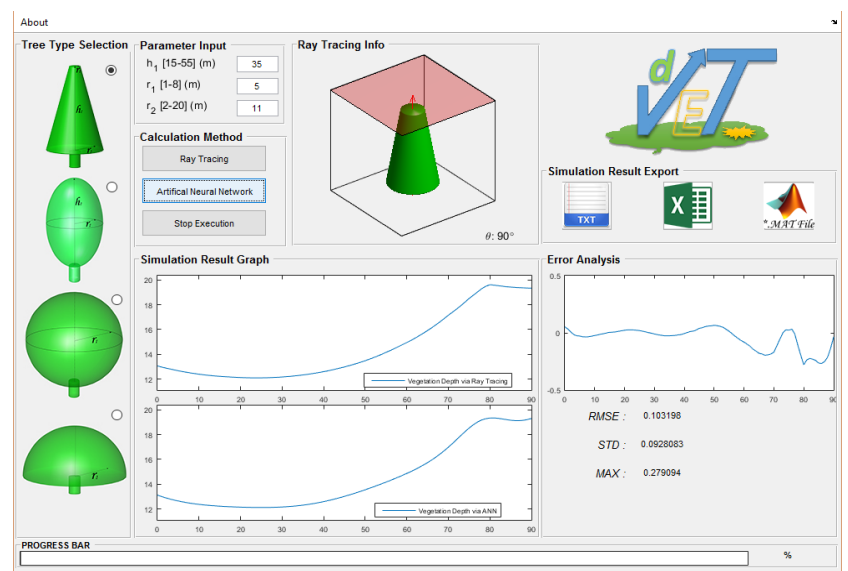

Fig. 10. GUI at the final stage. 


\section{Numerical Results}

The experimental studies in the literature contain only average tree attenuations and there are no detailed data about the measured tree parameters $\left(h_{1}, r_{1}, r_{2}\right)$ or the measured tree canopy (ellipsoid, conic, etc.). In other words, these studies cannot provide required data for a direct comparison. To be able to validate the proposed ray tracing method, we need to produce comparable results to the experimental studies. References [1], [2], [3], [7], [9] provide the average single tree attenuations obtained from measurements at UHF, L and $\mathrm{K}$ band. So, it is possible to compare the average single tree attenuations calculated via VdET tool with the provided ones in [1], [2], [3], [7], [9] by utilizing ray tracing method. Firstly, for every geometrical shape trees (conic, ellipsoid etc.), vegetation depths $(d)$ are calculated with the parameters used at training stage which are given in (1-4). Then, average single tree attenuation values are obtained by (5) at UHF, L and $\mathrm{K}$ band for full foliage condition. Obtained results are given in Tab. 6 in detail.

$$
L=A d^{B} f^{C}
$$

$L$ is attenuation in $\mathrm{dB}, f$ is frequency in $\mathrm{GHz}$ and $d$ represents vegetation depth in meters. For the full leaf condition, coefficients $A, B$ and $C$ are $1.43,0.721$ and 0.356 , respectively [18]. This model gives direct path attenuation without considering the diffracted components. Thus, it is agreeing with the calculation of vegetation depth via ray tracing.

\begin{tabular}{|c|c|c|c|c|c|c|c|}
\hline & \multicolumn{4}{|c|}{ UHF } & \multirow{2}{*}{\multicolumn{2}{|c|}{$\begin{array}{l}\mathrm{L} \text { band } \\
1.6 \mathrm{GHz}\end{array}$}} & \multirow{3}{*}{$\frac{\text { K band }}{20 \mathrm{GHz}}$} \\
\hline & \multicolumn{2}{|c|}{$800 \mathrm{MHz}$} & \multicolumn{2}{|c|}{$870 \mathrm{MHz}$} & & & \\
\hline & 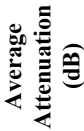 & 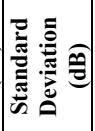 & 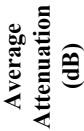 & 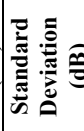 & 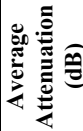 & 施 & \\
\hline Conic & 8.10 & 1.93 & 8.33 & 1.98 & 10.35 & 2.46 & 23.43 \\
\hline Ellipsoid & 6.03 & 1.84 & 6.21 & 1.89 & 7.72 & 2.35 & 16.98 \\
\hline Spherical & 11.40 & 1.83 & 11.74 & 1.87 & 14.59 & 2.33 & 29.83 \\
\hline Hemispherical & 10.12 & 3.60 & 10.42 & 3.70 & 12.95 & 4.60 & 33.85 \\
\hline Proposed & 8.91 & 2.3 & 9.18 & 2.36 & 11.40 & 2.93 & 26.02 \\
\hline Cavdar [7],[9] & 8.60 & 2.00 & -- & -- & 11.00 & 3.00 & -- \\
\hline $\begin{array}{c}\text { Vog. \& Gold. } \\
{[1],[2],[3]}\end{array}$ & -- & -- & 10.6 & 2.6 & -- & -- & 23.00 \\
\hline
\end{tabular}

Tab. 6. Comparison of the calculated average single tree attenuations with experimental results at $\mathrm{UHF}, \mathrm{L}$ and $\mathrm{K}$ bands (for $\theta=30^{\circ}$ ).

The average single tree attenuations are $8.91 \mathrm{~dB}$, $9.18 \mathrm{~dB}$ and $11.40 \mathrm{~dB}$ at UHF $(800 \mathrm{MHz})$, UHF $(870 \mathrm{MHz})$ and $\mathrm{L}$ band $(1.6 \mathrm{GHz})$, respectively. The median single tree attenuation at $\mathrm{K}$-band $(20 \mathrm{GHz})$ is calculated $26.02 \mathrm{~dB}$. It is clearly shown that the results are quite close with the other experimental results. These comparisons are made at given elevation angle, $\theta=30^{\circ}$. With the help of VdET tool, these average attenuation calculations can be made for each elevation angle $\left(0^{\circ}-90^{\circ}\right)$ at desired frequency band even for different tree types.
After validating ray tracing method, the purpose is to calculate vegetation depth for different tree types not only accurately but also faster. Thus, ANN is tested for calculation speed in Tab. 7. against ray tracing method. ANN method is faster than ray tracing minimally 11.65 times and maximally 716.41 times. These tests are conducted on a laptop with Core 17 processor and 16 GB RAM.

\begin{tabular}{|c|c|c|c|c|}
\hline \multirow{2}{*}{ Tree Types } & \multicolumn{2}{|c|}{ Ray Tracing } & \multicolumn{2}{c|}{ ANN } \\
\cline { 2 - 5 } & $\begin{array}{c}\text { For min. } \\
\text { volume }\end{array}$ & $\begin{array}{c}\text { For max. } \\
\text { volume }\end{array}$ & $\begin{array}{c}\text { For min. } \\
\text { volume }\end{array}$ & $\begin{array}{c}\text { For max. } \\
\text { volume }\end{array}$ \\
\hline Conic & $24.43 \mathrm{~s}$ & $458.5 \mathrm{~s}$ & $0.9 \mathrm{~s}$ & $0.64 \mathrm{~s}$ \\
\hline Ellipsoidal & $8.81 \mathrm{~s}$ & $121.31 \mathrm{~s}$ & $0.91 \mathrm{~s}$ & $0.64 \mathrm{~s}$ \\
\hline Spherical & $32.88 \mathrm{~s}$ & $92.37 \mathrm{~s}$ & $0.61 \mathrm{~s}$ & $0.61 \mathrm{~s}$ \\
\hline Hemispherical & $7.22 \mathrm{~s}$ & $257.13 \mathrm{~s}$ & $0.62 \mathrm{~s}$ & $0.62 \mathrm{~s}$ \\
\hline
\end{tabular}

Tab. 7. Ray tracing and ANN run time comparison for min. and max. tree volumes.

To accept the proposed ANN method instead of ray tracing, it should be tested for accuracy. Fig. 11, Fig. 12, Fig. 13 and Fig. 14 show comparative calculations of ray tracing and ANN methods with respect to vegetation depth for max. and min. foliage volumes.

In Tab. 8, statistics of errors in meters in Fig. 11, Fig. 12, Fig. 13 and Fig. 14 are listed. These values support the proposal of using ANN instead of ray tracing.

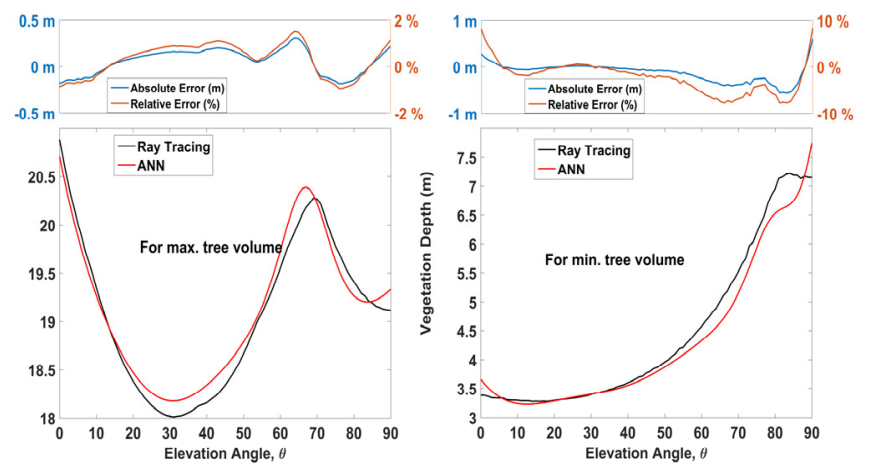

Fig. 11. Comparison of ray tracing and $A N N$ methods for max. and min. foliage volumes for conic shape trees. \{max. vol. $=24247.85 \mathrm{~m}^{3},\left(h_{1}, r_{1}, r_{2}\right)=(55,1,20)$; min. vol.= $\left.204.2 \mathrm{~m}^{3},\left(h_{1}, r_{1}, r_{2}\right)=(15,1,3)\right\}$

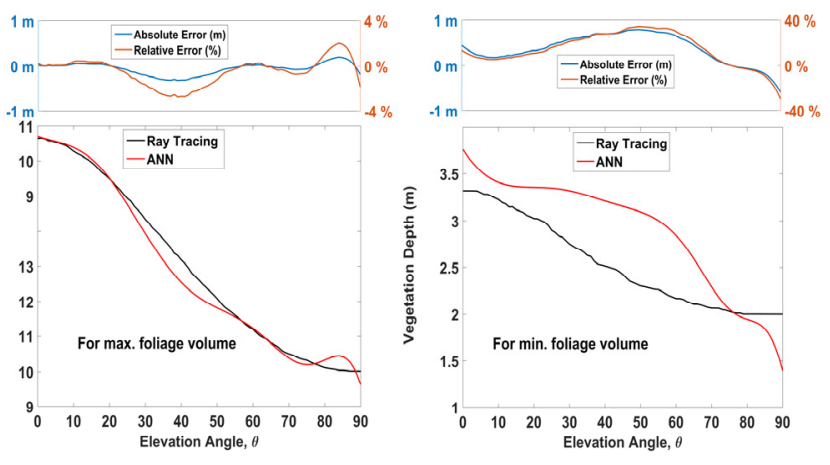

Fig. 12. Comparison of ray tracing and ANN methods for max. and min. foliage volumes for ellipsoid shape trees. $\left\{\right.$ max. vol. $=3141.6 \mathrm{~m}^{3},\left(h_{1}, r_{1}=(15,10)\right.$; $\mathrm{min}$. vol. $\left.=39.27 \mathrm{~m}^{3},\left(h_{1}, r_{1}\right)=(3,2.5)\right\}$ 

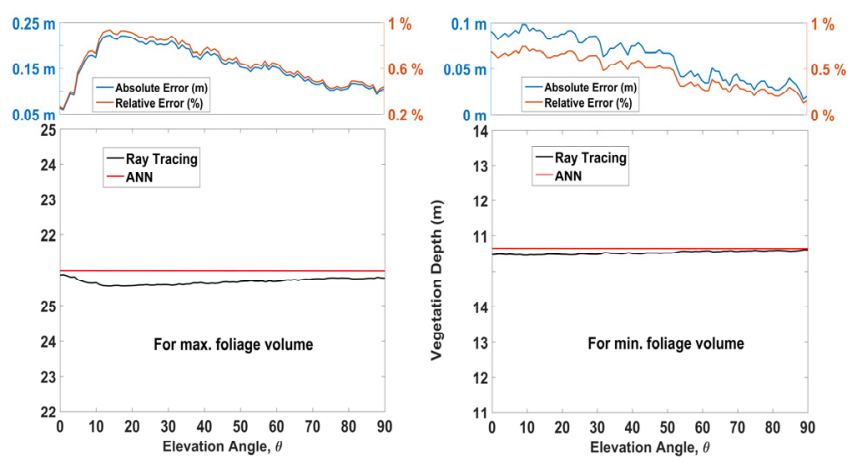

Fig. 13. Comparison of ray tracing and ANN methods for max. and $\min$. foliage volumes for spherical shape trees. $\left\{\right.$ max. vol. $=242429 \mathrm{~m}^{3},\left(r_{1}=18\right) ;$ min. vol.= $\left.4188.8 \mathrm{~m}^{3},\left(r_{1}=10\right)\right\}$
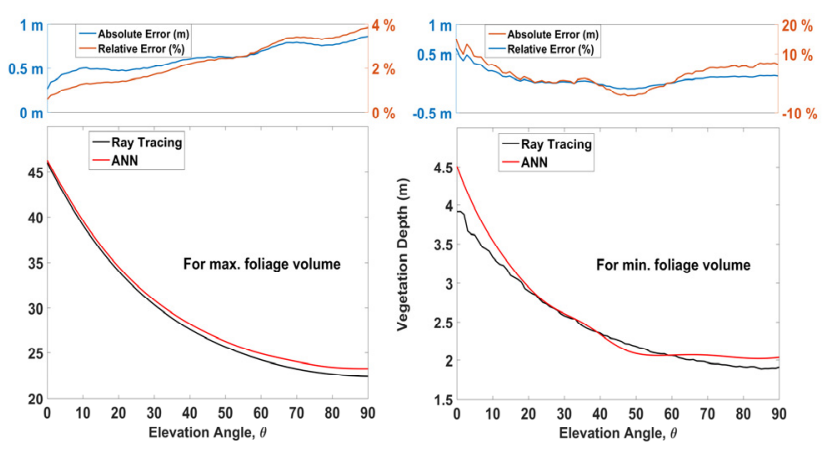

Fig. 14. Comparison of ray tracing and ANN methods for max. and min. foliage volumes for hemispherical shape trees. $\left\{\right.$ max. vol. $=89797 \mathrm{~m}^{3},\left(r_{1}=35\right)$; $\mathrm{min}$. vol. $=$ $\left.56.55 \mathrm{~m}^{3},\left(r_{1}=3\right)\right\}$

\begin{tabular}{|c|c|c|c|c|}
\hline \multirow{2}{*}{ Tree Type } & $\begin{array}{c}\text { Foliage } \\
\text { Volume }\end{array}$ & $\begin{array}{c}\text { RMS Error } \\
(\mathbf{m})\end{array}$ & $\begin{array}{c}\text { Std. of Error } \\
(\mathbf{m})\end{array}$ & $\begin{array}{c}\text { Max. Error } \\
(\mathbf{m})\end{array}$ \\
\hline \multirow{2}{*}{ Conic } & Max. & 0.1464 & 0.0623 & 0.3073 \\
\cline { 2 - 5 } & Min. & 0.2299 & 0.1645 & 0.6045 \\
\hline \multirow{2}{*}{ Ellipsoid } & Max. & 0.1459 & 0.1004 & 0.3257 \\
\cline { 2 - 5 } & Min. & 0.4904 & 0.2456 & 0.7931 \\
\hline \multirow{2}{*}{ Spherical } & Max. & 0.1617 & 0.0429 & 0.2228 \\
\cline { 2 - 5 } & Min. & 0.0665 & 0.0238 & 0.0984 \\
\hline \multirow{2}{*}{ Hemispherical } & Max. & 0.6326 & 0.1382 & 0.8616 \\
\cline { 2 - 5 } & Min. & 0.1524 & 0.1127 & 0.5899 \\
\hline
\end{tabular}

Tab. 8. Statistics of error in Fig. 11, Fig. 12, Fig. 13 and Fig. 14.

Mainly, there are two aspects of this study. The first one, a tool is created to calculate the vegetation depth of a single tree for different tree types with utilizing ray tracing method. The second one is to propose an alternative faster method (ANN) instead of ray tracing. Generally, a faster method brings some estimation error. Thus, to be able to exhibit the error performance of the ANN, a comparison is made in the simulation tool for all possible situations. Additionally, comparisons of ray tracing and ANN methods for max. and min. foliage volumes at different tree types are shown in Fig. 11, Fig. 12, Fig. 13 and Fig. 14. The maximum error of ANN is obtained for min. foliage volume ellipsoid shape tree. This is not an unexpected result. ANN training set consist of 25 trees which 8 of them is for ellipsoid shape trees. Ellipsoid tree model needs two input data $h_{1}$ and $r_{1}$. The variation ranges of

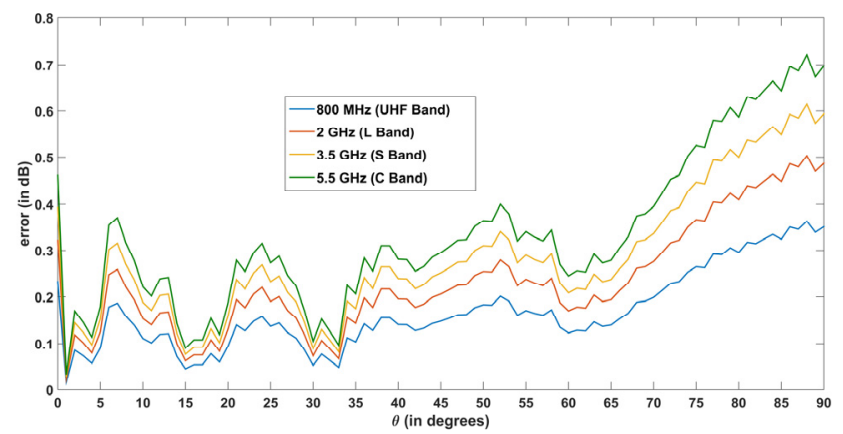

Fig. 15. ANN error in $\mathrm{dB}$ for hemispherical tree with $10 \mathrm{~m}$ radius.

these parameters are determined according to Tab. 3 and shown in (2). The mean $h_{1}$ value of ellipsoid shape tree is generally between $19.62 \mathrm{~m}-28.87 \mathrm{~m}$ (Tab. 3: Height column). The required $h_{1}$ value to calculate min. foliage volume for ellipsoid shape tree is $3 \mathrm{~m}$ as mentioned in Fig. 12. caption (min. vol. $\left.=39.27 \mathrm{~m}^{3},\left(h_{1}, r_{1}\right)=(3,2.5)\right)$. As a result, this $h_{1}$ value $(3 \mathrm{~m})$ is not included in ANN training set because it is considered as an outlier value. In this case, ANN makes an extrapolation instead of interpolation. Thus, this min. foliage volume error of ANN does not indicate the real ANN performance. Additionally, it is clearly seen from other error tests that ANN makes good approximations if the input values are within the training range.

On the other hand, giving error in meters is not enough to express what this means in real world. Vegetation depth is important to calculate excess loss (dB). Judging from here, the error is converted to $\mathrm{dB}$ with the help of the most common general form of existing empirical model in the literature [18] as shown in (5). In [12], a study is conducted on four different deciduous trees heights ranging between 11 to 18 meters and width between 11 to 20 meters which can be modeled in the tool as hemispherical. Hereby, the reference tree to show the error in $\mathrm{dB}$ is selected hemispherical with $10 \mathrm{~m}$ radius with respect to the (5) range. In Fig. 15, errors in $\mathrm{dB}$ according to elevation angles at four different frequency bands (UHF, L, S, and C) are shown.

\section{Conclusion}

In this study, tree types especially encountered in Black Sea region are classified according to their geometrical shape as conic, ellipsoid, spherical and hemispherical. Based on ray tracing and ANN method, a vegetation depth estimation tool (VdET) with a friendly GUI is proposed. The proposed method is validated with the related literature in terms of average single tree attenuation (Tab. 6). With the help of this tool, it is shown that same foliage volume trees with different geometries have different vegetation depths (Fig. 8). Additionally, ANN method is proposed as an alternative to ray tracing. The performance of ANN against ray tracing in the aspect of accuracy (Tab. 8) and speed (Tab. 7) is presented and concluded that using ANN is reasonable with an acceptable error tolerance (Fig. 15). 


\section{Acknowledgment}

The source code of the VdET can be accessed from http: //www.mathworks.com/matlabcentral/fileexchange/55787.

\section{References}

[1] VOGEL, W. J., GOLDHIRSH, J. Tree attenuations at $869 \mathrm{MHz}$ derived from remotely piloted aircraft measurements. IEEE Transactions on Antennas and Propagation, 1986 (current version 2003), vol. 34 , no. 12, p. 1460-1464. ISSN: 0018-926X. DOI: 10.1109/TAP.1986.1143781

[2] GOLDHIRSH, J., VOGEL, W. J. Roadside tree attenuation measurements at UHF for land-mobile satellite systems. IEEE Transactions on Antennas and Propagation, 1987 (current version 2003), vol. 35, no. 5, p. 589-596. ISSN: 0018-926X. DOI: 10.1109/TAP.1987.1144137

[3] VOGEL, W. J., GOLDHIRSH, J. Earth-satellite tree attenuation at $20 \mathrm{GHz}$ foliage effects. Electronics Letters, 1993 (current version 2002), vol. 29, no. 18 , p. 1640-1641. ISSN: 0013-5194. DOI: 10.1049/el:19931092

[4] BUTTERWORTH, J. S. Propagation Measurements for LandMobile Satellite Services at $1542 \mathrm{MHz}$. Tech. Note 723, Ottawa, ON (Canada): Commun. Res. Center, 1984.

[5] BUTTERWORTH, J. S. Propagation Measurements for LandMobile Satellite Services in the $800 \mathrm{MHz}$. Tech. Note 724, Ottawa, ON (Canada): Commun. Res. Center, 1984.

[6] Ulaby, F. T., WhiTT, M.W., DOBSON, M. C. Measuring the propagation properties of a forest canopy using a polarimetric scatterometer. IEEE Transactions on Antennas and Propagation, 1990 (current version 2002), vol. 38, no. 2, p. 251-258. ISSN: 0018-926X. DOI: 10.1109/8.45128

[7] CAVDAR, I. H. UHF and L-band propagation measurements to obtain log-normal shadowing parameters for mobile satellite link design. IEEE Transactions on Antennas and Propagation, 2003, vol. 51, no. 1, p. 126-130. ISSN: 0018-926X. DOI: 10.1109/TAP.2003.808545

[8] ITU-R. Propagation Data Required for the Design of Earth-Space Land Mobile Telecommunication Systems. Recommendation ITUR PN.681-1, International Telecommunication Union, ITU-R Recommendations, Propagation in Non-Ionized Media, 1994 PN Series Volume, p. 203-204. ISBN: 92-61-05171-5

[9] CAVDAR, I. H., DINCER, H., ERDOGDU, K. Propagation measurements at L-band for land mobile satellite link design. In Proc. 7th Mediterranean Electrotechnical Conference (MELCON). Antalya (Turkey), 1994, vol. 3, p. 1162-1165. DOI: 10.1109/MELCON.1994.380862

[10] Tree Attenuation at $20 \mathrm{GHz}$ : Foliage Effects. Presentations of the Sixth ACTS Propagation Studies Workshop (APSW VI), Clearwater Beach (Florida), 1994, p. 219-223. (Jet Propulsion Laboratory Technical Report, JPL D-12350, California Institute of Technology, Pasadena, California.)

[11] GOLDHIRSH, J., VOGEL, W. J. Mobile satellite system fade statistics for shadowing and multipath from roadside trees at UHF and L-band. IEEE Transactions on Antennas and Propagation, 1989 (current version 2002), vol. 37, no. 4, p. 489-498. ISSN: 0018-926X. DOI: 10.1109/8.24169

[12] HORAK, P., PECHAC, P. Excess loss for high elevation angle links shadowed by a single tree: Measurements and modeling. IEEE Transactions on Antennas and Propagation, 2012, vol. 60, no. 7, p. 3541-3545. DOI: 10.1109/TAP.2012.2196944
[13] HORAK, P., KVICERA, M., PECHAC, P. Frequency dependence of attenuation due to vegetation for satellite services. IEEE Antennas Wireless Propagation Letters, 2010, vol. 9, p. 142-145. ISSN: 1536-1225. DOI: 10.1109/LAWP.2010.2045150

[14] HORAK, P., PECHAC, P. Seasonal additional attenuation in woodlands for satellite services at L-, S- and C- bands. IEEE Transactions on Antennas and Propagation, 2011, vol. 59, no. 12, p. 4865-4867. DOI: 10.1109/TAP.2011.2165507

[15] KARLSSON, A., SCHUH, R. E. BERGLJUnG, C., et al. The influence of trees on radio channel at frequencies of 3 and $5 \mathrm{GHz}$. In Proc. IEEE 54th Vehicular Technology Conf. (VTC 2001). Atlantic City (NJ), 2001, vol. 4, p. 2008-2012. ISSN: 1090-3038. DOI: $10.1109 /$ VTC.2001.957096

[16] ITU-R. Attenuation in Vegetation. Recommendation ITU-R P.8336, 2007, International Telecommunication Union, ITU-R Recommendations.

[17] GOLDHIRSH, J., VOGEL, W. J. Handbook of Propagation Effects for Vehicular and Personal Mobile Satellite Systems Overview Experimental and Modeling Results. $2^{\text {nd }}$ ed. Houston (TX): NASA, 1999.

[18] COST 235. Radiowave Propagation Effects on Next Generation Fixed Services Terrestrial Telecommunications Systems. Commission of the Eur. Union, 1996, Final Rep. ISBN: 92-8278023-6

[19] ANSIN, R., OZKAN, Z. C. Tohumlu Bitkiler-Odunsu Taksonlar (Spermatophyta) [Seed Plants-Woody Taxa (Spermatophyta)]. $2^{\text {nd }}$ ed. Trabzon (Turkey): Karadeniz Technical University, 1997. ISBN: 975-6983-00-0

\section{About the Authors ...}

Zeynep HASIRCI was born in Samsun, Turkey. She received B.Sc. and M.Sc. degrees from Karadeniz Technical University (KTU) in 2008 and 2011, respectively. She studied for her Ph.D. thesis in Halmstad University, Sweden for one year. She is currently a Ph.D. student at the Department of Electrical and Electronics Engineering, KTU. Her research interests include communication systems, mobile and satellite communication, propagation modeling and power line communication.

Ismail Hakki CAVDAR was born in Trabzon, Turkey. He received his Ph.D. degree in Electrical and Electronics Engineering from Karadeniz Technical University (KTU), in 1994. He has been a Full Professor at KTU since 1985. He was a Visiting Professor at Smart Grid Lab in the Department of Electrical and Computer Engineering, The University of Akron, OH USA, in 2011. His research interests include communications systems, mobile and satellite communication, power line communications, smart grids and power electronics.

Mehmet OZTURK was born in Trabzon, Turkey. He received his B.Sc degree in Electronics Engineering from Kadir Has University in 2004. He received his M. Sc. and $\mathrm{Ph} . \mathrm{D}$. degrees in Electrical and Electronics Engineering from Karadeniz Technical University (KTU) in 2007 and 2013, respectively. His research interests include biomedical, signal and image processing, point clouds. 